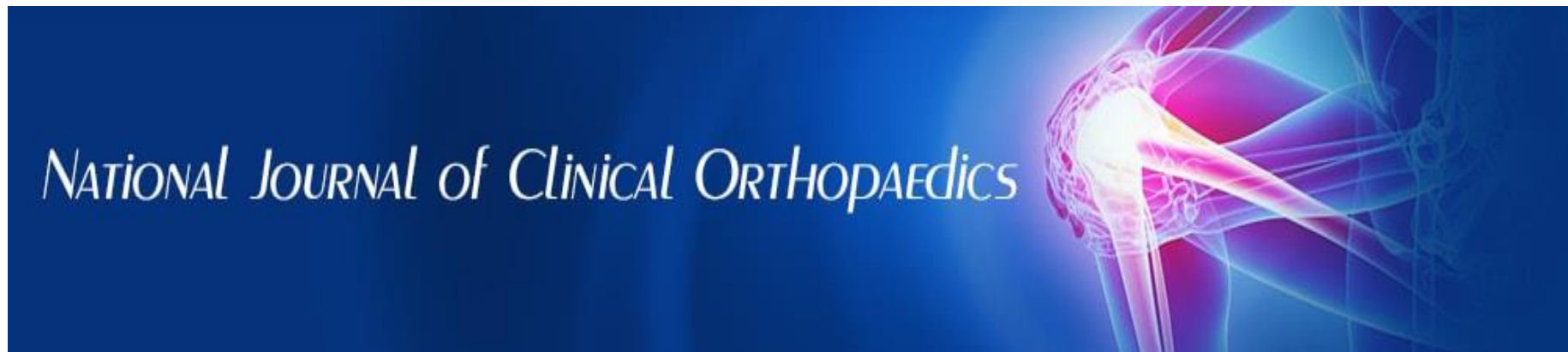

ISSN (P): 2521-3466

ISSN (E): 2521-3474

(C) Clinical Orthopaedics

www.orthoresearchjournal.com

2019; 3(1): 128-130

Received: 08-11-2018

Accepted: 11-12-2018

Dr. Suganthi David D

Associate Professor,

Department of Orthopedics,

Mount Zion Medical College,

Chayalode, Adoor, Kerala, India

Dr. Anilkumar SD

Associate Professor,

Department of Orthopedics,

Mount Zion Medical College,

Chayalode, Adoor, Kerala, India

Correspondence

Dr. Anilkumar SD

Associate Professor,

Department of Orthopedics,

Mount Zion Medical College,

Chayalode, Adoor, Kerala, India

\section{Functional evaluation of intra articular fractures of distal humerus in adults after open reduction and internal fixation}

\section{Dr. Suganthi David D and Dr. Anilkumar SD}

DOI: https://doi.org/10.33545/orthor.2019.v3.i1c.25

\section{Abstract}

The result of operative fixation of fractures of the distal humerus remained unpredictable until improved techniques for the fixation of small, articular fractures as developed by the Arbeitsgemeinschaft fur osteosynthesefragen / association for the study of internal fixation and others were applied. On the basis of the results reported in the more recent series, fixation with two plates of 90 degrees angle with one another has become the standard against which all other treatments are measured. The study was conducted in Medical College, and there were 14 cases in the study in which 9 were males and 5 females. Age of the patients ranged between 25 years and 75 years with an mean age of 48.2 years. Among the 14 cases, 8 were caused by fall (57\%) and six were caused by Road Traffic accidents (43\%).Two patients in our series had mild infection. Ulnar neuropathy, Tournequette palsy and Non-union were reported one each.3 patients had pain due to protruding screws. None in the series had vascular complications and none developed heterotopic ossification.

Keywords: Functional evaluation, intra articular fractures of distal humerus, open reduction and internal fixation

\section{Introduction}

The quality of elbow function after fracture of the distal humerus is related to the degree to which the normal anatomical relationships are restored. Elbow mobility is hindered by loss of normal 30 degrees anterior tilt of the distal humeral articular surface, by narrowing or distortion of the trochlear articular surface, and by obstruction of the coronoid and olecranon fossae. Pin can be related to failure of fracture to unite restricted motion, ulnohumeral arthosis or instability, and compression of the ulnar nerve ${ }^{[1]}$.

The only reliable method for restoring the normal alignment and contour of the distal humerus operative exposure and direct manipulation of fracture fragments. However, fixation of fracture fragments must be stable enough to allow motion while ensuring union. In the early and' middle parts of twentieth century, operative treatment was combined with devascularizing exposure, inadequate fixation and cast immobilisation. The result was often elbow stiffness and delayed healing. In this context, nonoperative treatments, such as the so-called bag-ofbones technique (a short duration of immobilisation in either a cast or a collar and cuff followed by mobilisation as tolerated) were established as treatment alternatives ${ }^{[2]}$.

The result of operative fixation of fractures of the distal humerus remained unpredictable until improved techniques for the fixation of small, articular fractures as developed by the Arbeitsgemeinschaft fur osteosynthesefragen / association for the study of internal fixation and others were applied. On the basis of the results reported in the more recent series, fixation with two plates of 90 degrees angle with one another has become the standard against which all other treatments are measured. Despite the confidence in operative fixation, these remain challenging fractures to treat effectively and best managed by surgeons with interest and experience in skeletal trauma with upper extremity ${ }^{[3]}$. Even the most experienced surgeons, however may be intimidated with certain fracture characteristics, including poor bone quality, fractures involving the distal most aspects of the bone columns, and fragmentation of articular surface in sagittal and coronal planes. A surgeon treating a healthy active patient with a fracture of distal humerus should make every effort to reconstruct and preserve the distal humeral articular surface ${ }^{[4]}$. 


\section{Methodology}

The study was conducted in Medical College, and there were 14 cases in the study in which 9 were males and 5 females Age of the patients ranged between 25 years and 75 years with an mean age of 48.2 years.

Among the 14 cases, 8 were caused by fall (57\%) and six were caused by Road Traffic accidents (43\%) Factures were classified using Riseborough and Radin classification.

Inclusion Criteria: All cases of closed intraarticular fractures of distal humerus in adults

Exclusion Criteria: Open fractures, pathological fracture, Poly trauma.

\section{Technique}

- All cases were done under general anaesthesia.

- Pre-operative antibiotics were given.

- Prone position with elbow flexed over arm board or lateral decubitus position with pillow under arm.

- Tourniquet applied

- Majority of cases were done by Campbells posterior approach.

- Ulnar nerve identified and retracted gently with tape.

- Tongue of ticeps apponeurosis raised.

- Triceps split in midline and tissues retracted sub periosteally.

- Joint surface reconstruction done first.

- Preliminary fixation of joint fragments by $\mathrm{K}$ wire followed by permanent fixation with cancellous or cortical lag crews.

- Reduction and fixation of reassembled condyles to metaphysis with plates or lag screws, ideally by hand contoured $3.5 \mathrm{~mm}$ reconstruction plate or DCP applied on posterior aspect of lateral pillar and one third tubular plate applied at $90^{\circ}$ on medical humeral pillar.

- The tongue defect of triceps aponeurosis repaired.

- Wound closed in layers.

- Above elbow slab applied.

\section{Results}

The cases were followed up regularly and assessed using Mayo Elbow Performance Index. Evaluation of results consisted of objective and subjective assessment considering pain, limitation of elbow movement, instability and functional activities, Index gives maximum weightage to pain, functional activities and range of movement.

Table 1: Mayo Elbow Performance Index

\begin{tabular}{|c|c|c|c|}
\hline Function & Maximum Points & Definition & Points \\
\hline \multirow{4}{*}{ Pain } & \multirow{4}{*}{45} & None & 45 \\
\hline & & Mild & 30 \\
\hline & & Moderate & 15 \\
\hline & & Severe & 0 \\
\hline \multirow{3}{*}{ Motion } & \multirow{3}{*}{10} & ARC $>100^{\circ}$ & 20 \\
\hline & & $50^{\circ}-100^{\circ}$ & 15 \\
\hline & & $<50^{\circ}$ & 5 \\
\hline \multirow{3}{*}{ Stabiity } & \multirow{3}{*}{10} & Stable & 10 \\
\hline & & Moderate instability & 5 \\
\hline & & Gross instability & 0 \\
\hline \multirow{5}{*}{ Function } & \multirow{5}{*}{25} & Comb hair & 5 \\
\hline & & Feed & 5 \\
\hline & & Hygiene & 5 \\
\hline & & Shirt & 5 \\
\hline & & Care of foot & 5 \\
\hline
\end{tabular}

Grading: Excellent > 90; Good 75-89; Fair 60-74, Poor $<60$

Results were considered acceptable if Mayo elbow performance index (MEPI) score is excellent or good un acceptable if fair or poor. of the 14 patients studied, 10 patients $(71.42 \%)$ had good or excellent outcome (average score 85.5). while 4 patients $(28.58 \%)$ had fair or poor functional outcome (average score $61.25 \%$ ). Highest score obtained was 100 and lowest score was 45 .

Annova test was conducted and the observed differences are statistically significant. (P value <.001).

Table 2: Comparison of mean MEPI score at onset and final follow up

\begin{tabular}{|c|c|c|c|c|}
\hline & Mean & $\mathbf{\pm}$ SD & t value & P value \\
\hline MEPI Score Onset & 48.21 & 8.68 & \multirow{2}{*}{5.238} & $<0.001$ \\
\hline MEPI Score final Follow up & 74.29 & 10.69 & & \\
\hline
\end{tabular}

Two patients who were immobilised by above elbow slab for 10 days and then mobilised had excellent results (average score 97.5\%).

Among 10 patients who were immobilised with above elbow slab for 3 weeks, 8 had acceptable results (average score 82.5\%) and 2 had non-acceptable results (average score - 70\%).

Both the patients who were immobilised by above elbow slab for 6 Weeks had unacceptable results (average score 52.5\%).

ANNOVA test was conducted and observed differences are found be statically significant $(\mathrm{P}$ Value $<.05)$.

Table 3: Comparison of mean MEPI score at onset and final follow up

\begin{tabular}{|c|c|c|c|c|c|}
\hline & Length of Immobilisation & Mean & $\mathbf{\pm S D}$ & F value & P value \\
\hline \multirow{2}{*}{$\begin{array}{c}\text { MEPI Score } \\
\text { Onset }\end{array}$} & AE Slab/ 3 wks & 49.50 & 7.25 & \multirow{3}{*}{4.820} & \multirow{3}{*}{$<0.05$} \\
\cline { 2 - 4 } & AE Slab/ 6 wks & 35.00 & 7.07 & \\
\cline { 2 - 4 } $\begin{array}{c}\text { MEPI score } \\
\text { Final follow up }\end{array}$ & AE Slab/10 days & 55.00 & 0.00 & & \\
\cline { 2 - 4 } & AE Slab/ 3 wks & 74.00 & 9.23 & \multirow{2}{*}{3.699} & \multirow{2}{*}{$<0.05$} \\
\cline { 2 - 4 } & AE Slab/ 6 wks & 52.50 & 3.54 & & \\
\hline
\end{tabular}

Two patients in our series had mild infection. Ulnar neuropathy, Tournequette palsy and Non-union were reported one each. 3 patients had pain due to protruding screws. None in the series had vascular complications and none developed heterotopic ossification.

\section{Discussion}

The successful treatment of any articular fracture demands an anatomic reduction of the joint surface and the ability to allow early motion.

Most inter condylar fractures of the distal humerus are displaced and requires anatomical reduction. Because of the deforming forces across the elbow joint, reduction without stable fixation is generally not successful. Stable fixation of the condyles of the distal humerus to the shaft is not without its own inherent problems, the anatomic constrains of the elbow joint (both bone and soft tissue) and the difficulty in obtaining distal fixation, 
particularly when there is intercondylar or supracondylar comminution (or both), further compounded by the presence of osteopenia. To obtain reproducible results, an established protocol is required. This demands a careful evaluation and preoperative planning, and surgical 'tactic' that includes anatomical restoration of the articular surface and stable fixation of the condyles to the shaft. Postoperatively, stable fixation allows early, active, aggressive mobilisation. By strict adherence to this protocol, the literature supports excellent and good results in the surgical treatment of these difficult bicondylar intraarticular fractures of the distal humerus in $75 \%$ of cases ${ }^{[5]}$.

In our study, $71 \%$ of the patients had good or excellent outcome after open reduction and internal fixation. Age of the patient did not affect the functional outcome.

In our study we used the fracture classification according to Riseborough and Radin. Since X-rays are poor indicator of intraarticular comminution, for a better picture CT Scan is advised but final picture is complete only on the operating table after the fracture site is exposed.

Jupiter noted that, final functional out come of simple articular (Type II \& III) and comminuted articular fractures (Type IV) are similar though range of movement will be less in latter. In our study better than comminuted articular (Type IV) fracture ${ }^{[6]}$.

Literature mentions that Open reduction should be done at the earliest or it will influence the final outcome, but no specific time period is mentioned ${ }^{[7,8]}$. Surgery done as early as 24 hours helps to prevent the occurrence of heterotropic ossification. In our study earliest surgery was done at 8 hours after injury and extended up to 15 days. The delay was mainly due to the delay in referral from the peripheral centres, fitness for surgery and delay by patients to seek medical attention. In our study we found there is no statistically significant difference in the functional outcome of patients whose surgery was done before the mean time of 6 days and after 6 days.

Aitken and Rorabeck showed in their study that patient with prolonged immobilisation ( $>4$ weeks) or delayed mobilisation had poor results. In our study range of movement and functional outcome was better in all cases mobilised early ${ }^{[9,10]}$.

Average arc of motion was $15-125^{\circ}$ in patients mobilized from 10 th post-operative day. While it was $29-108^{\circ}$ in patients mobilized after 3 weeks and $40--90^{\circ}$ in those mobilised after 6 weeks.

Studies by Mckee, Kin and Kebash showed mean flexion deformity of $25^{\circ}$ in their study. In our series mean flexion deformity was $26^{\circ}$ (Range 10-40) ${ }^{[8]}$.

We preferred immobilisation up to 3 weeks to prevent wound dehiscence infection and give time for the intra articular fragments, not fixed by lag screws, to fall in alignment.

Immediate post- operative complications were ulnar nerve palsy in one case where $\mathrm{K}$ wire was used and one case of tourniquet palsy, both recovered completely in 6 months. Mild infection was seen in 2 cases which was controlled by antibiotics. Delayed complication like non-union was noted in one case which was later treated by total elbow arthroplasty. We did not have single case of heterotropic ossification in our series. This may be due to absence of head injury or severe infection which are considered to be main causes of heterotropic ossification.

\section{Conclusion}

- Patients who were mobilised earlier had better functional outcome.

- Complications like ulnar nerve palsy, non-union and hardware pain were similar to other studies. No vascular complications or heterotropic ossification was noted.
- Careful pre-operative planning, anatomical reconstruction of articular surface, stable fixation and early active mobilisation are essential for getting an excellent functional outcome.

\section{References}

1. Jupiter JB, Neff U. Holzach P. Intercondylar fractures of the Humerus: An operative approach. J Bone Joint surg Am. 1985; 67:226-238.

2. Riseborough EJ, Radin EL. Intercondylar T fractures of the humerus in the adults. J Bone Joint Surg Am. 1969; 51:130138.

3. Holdsworth BL, Mossad MM. Fractures of the adult distal humerus: Elbow function after internal fixation $\mathrm{J}$ Bone Joint Surg Br. 1990; 72B:362-268.

4. Cobb TK, Morrey BF. Total elbow arthroplasty as primary treatment for distal humerus fractures in elderly patients. J Bone Joint Surg Am. 1997; 79:826-832.

5. Watson Jones R. Fractures \& Joint injuries, Baltimore. William \& Wilkin, 1946.

6. Bickel WE, Perry RE. Comminuted Fractures of the Distal Humerus. J.A.M.A. 1963; 184:553-55.

7. Rock wood \& Green's - Fractures in Adults ( $4^{\text {th }}$ ed.) Lippincott Raven, 943-953.

8. Johansson H, Olerud S. Operative Treatment of Intercondylar Fractures of the Humerus. J Trauma. 1971; 11:836-843.

9. Riseborough EJ, Radin EL. Intercondylar T fractures of the Humerus in the adult. A Comparison of Operative and Nonoperative Treatment in Twenty-nine cases. J Bone Joint Surg. 1969; 51A:130-141.

10. Muller ME, Allgower $M$, Schneider $R$, Willeneger $H$. manual of Internal Fixation, $2^{\text {nd }}$ ed. New Yor, SpringerVerlag, 1979. 